\title{
ÍNDICE DE AUTORES
}

$\begin{array}{ll}\text { Andre Vinicius Lopes CONEGLIAN } & 249\end{array}$

Eliana Rosa STURZA 56

$\begin{array}{ll}\text { Enedino SOARES } & 145\end{array}$

$\begin{array}{lr}\text { Eric LAPORTE } & 204\end{array}$

$\begin{array}{lr}\text { Giovana Cristina de MOURA } & 169\end{array}$

$\begin{array}{ll}\text { Gladys QUEVEDO-CAMARGO } & 230\end{array}$

$\begin{array}{lr}\text { Gustavo Ximenes CUNHA } & 10\end{array}$

$\begin{array}{ll}\text { Heloisa Mara MENDES } & 101\end{array}$

Jorge Viana SANTOS 35

$\begin{array}{ll}\text { Juliana Reichert Assunção TONELLI } & 230\end{array}$

Kelly Cristini GRANZOTTO WERNER 56

$\begin{array}{ll}\text { Larissa PICOLI } & 204\end{array}$

Liliana de Almeida Nascimento FERRAZ 35

$\begin{array}{ll}\text { Luciane de PAULA } & 169\end{array}$

$\begin{array}{ll}\text { Marcela Langa LACERDA } & 68\end{array}$

$\begin{array}{ll}\text { Marilza de OLIVEIRA } & 145\end{array}$

$\begin{array}{ll}\text { Marina Célia MENDONÇA } & 101\end{array}$

$\begin{array}{ll}\text { Oto Araújo VALE } & 204\end{array}$

$\begin{array}{lr}\text { Sonia MERITH-CLARAS } & 129\end{array}$ 